Gut and Liver, Vol. 9, No. 5, September 2015, pp. 672-678

\title{
Efficacy and Safety of Pancreatobiliary Endoscopic Procedures during Pregnancy
}

Jae Joon Lee, Sung Koo Lee, Sang Hyung Kim, Ga Hee Kim, Do Hyun Park, Sangsoo Lee, Dongwan Seo, and Myung-Hwan Kim Department of Gastroenterology, Asan Medical Center, University of Ulsan College of Medicine, Seoul, Korea

See editorial on page 569.

Background/Aims: Endoscopic therapy with endoscopic retrograde cholangiopancreatography (ERCP) has been suggested as an effective diagnostic and therapeutic tool for biliary and pancreatic disorders during pregnancy. In this report, we describe our experiences with pancreatobiliary endoscopic procedures during pregnancy. Methods: We reviewed ERCP and endoscopic ultrasonography (EUS) procedures that were performed at a single tertiary care referral center between January 2002 and October 2013. Medical records were reviewed for the procedure indication, the duration of fluoroscopy, postprocedure complications, etc. Pregnancy outcomes and fetal complications were identified by chart review and phone calls to patients. Results: A total of 10 ERCPs and five EUSs were performed in 13 pregnant patients: four of whom underwent the procedure in the first trimester, eight in the second trimester, and one in the third trimester. Indications for endoscopic therapy included gallstone pancreatitis, obstructive jaundice with common bile duct (CBD) stone, asymptomatic CBD stone, pancreatic cyst, choledochal cyst, and acute cholecystitis. Only one patient had a complication, which was postprocedural hyperamylasemia. Two patients underwent an artificial abortion, one according to her own decision and the other due to an adverse drug reaction. Conclusions: ERCP seems to be effective and safe for pregnant women. Additionally, EUS can be an alternative to ERCP during pregnancy. (Gut Liver 2015;9:672-678)

Key Words: Cholangiopancreatography, endoscopic retrograde; Endosonography; Pregnancy; Fetus

\section{INTRODUCTION}

The frequency of choledocholithiasis requiring therapeutic intervention is rare and has been estimated to be as low as one in 1,200 deliveries. ${ }^{1}$ However, choledocholithiasis can be a serious condition leading to potentially life-threatening consequences for both mother and fetus. Endoscopic therapy with endoscopic retrograde cholangiopancreatography (ERCP) has been suggested as an effective and safe therapeutic option for these conditions during pregnancy. And endoscopic ultrasound (EUS) has also been used as an alternative or ancillary procedure for ERCP.

In this report, we describe our experiences with endoscopic management of biliary and pancreatic disorders in 13 pregnant patients.

\section{MATERIALS AND METHODS}

We reviewed ERCP and EUS data from our endoscopy database which was performed in reproductive age (18 to 45 years) women between January 2002 and October 2013. ERCP and EUS were performed using Olympus TJF 260V (Olympus, Tokyo, Japan) and GF UCT 260 (Olympus) videoendoscope system, respectively. And digitalized fluoroscopy system (Hitachi TU8000DR) was used to get images of biliary tree and pancreatic duct. In most cases, procedures were performed in the left lateral decubitus position to avoid compromise of venous return including one patient at the later stage of pregnancy. Endoscopic procedures were performed with conscious sedation by using midazolam occasionally and pethidine was given to all patients for pain control. Patients were monitored by pulse oximetry during the procedure. Prophylactic antibiotics such as cefotaxime or ceftizoxime were administered to those patients who

\footnotetext{
Correspondence to: Sung Koo Lee

Department of Gastroenterology, Asan Medical Center, University of Ulsan College of Medicine, 88 Olympic-ro 43-gil, Songpa-gu, Seoul 138-736, Korea

Tel: +82-2-3010-3186, Fax: +82-2-476-0824, E-mail: sklee@amc.seoul.kr

Received on June 6, 2014. Revised on October 22, 2014. Accepted on November 24, 2014. Published online June 19, 2015 pISSN 1976-2283 eISSN 2005-1212 http://dx.doi.org/10.5009/gnl14217

@) This is an Open Access article distributed under the terms of the Creative Commons Attribution Non-Commercial License (http://creativecommons.org/licenses/by-nc/4.0) which permits unrestricted non-commercial use, distribution, and reproduction in any medium, provided the original work is properly cited.
} 
have potential need for sphincterotomy or other therapeutic interventions. The pelvis of all patients who had notified of their pregnancy was lead-shielded to minimize radiation exposure to the fetus (Fig. 1).

Although we had no specific protocol with regard to fluoroscopy use in pregnant patients, fluoroscopy was minimized and imaging was used if required but only for a short duration. We occasionally attempted nonfluoroscopy cannulation by using bile aspiration for the patients who are in their first trimester. Endoscopic sphincterotomy was carried out by using bipolar current when required. After the procedures, patients were monitored for immediate complications and were followed up daily until discharge.

We collected data including patients' gestational age, clinical presentations, results of laboratory investigations, progress of pregnancy, mode of delivery, health condition of mother and fetus at the time of delivery and follow-up results. We also collected procedural data such as sedation methods, duration of procedures, monitoring methods, duration of fluoroscopy and intervention outcomes. In particular, we tried to contact the

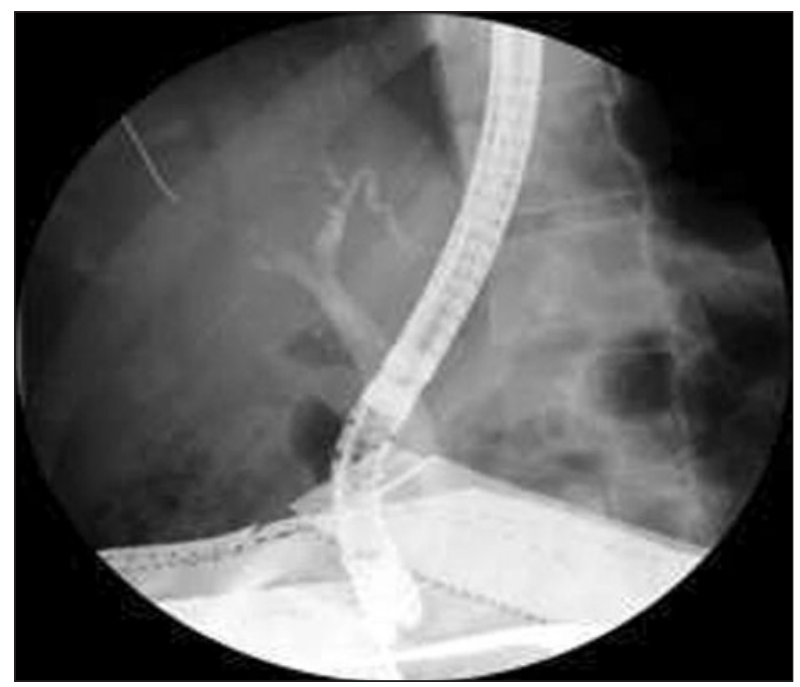

Fig. 1. The pelvis of the patient was covered with a lead apron (case 4). patients by phone to collect long-term follow-up results about health condition of their children.

\section{RESULTS}

A total of 10 ERCPs and five EUSs were performed in 13 pregnant women between January 2002 and October 2013. The mean age of the patients was 30.7 years old (range, 22 to 41 years) and the mean duration of gestation was 16.8 weeks (range, 6 to 32 weeks). Four patients were in the first trimester, eight in the second and one in the third trimester.

Medications which were used for sedation and pain control did not cause any complications such as hypoxia, arrhythmias, or hypotension.

The indications were mainly gallstone pancreatitis, common bile duct (CBD) stone with or without obstructive jaundice. Other indications include traumatic pancreatitis, acute cholecystitis, choledochal cyst with or without cholangitis and mucinous cystic neoplasm.

Before the procedure, abdominal ultrasound or magnetic resonance cholangiopancreatography (MRCP) was performed in all patients to make a diagnosis. We also used EUS to classify cystic structure or to examine spontaneous passage of stone (Fig. 2). Computed tomography (CT) was performed in one patient at the secondary general hospital as she did not inform of her pregnancy to medical team at that time (case 9). They found out from the CT image that she had a bile duct cyst and they transferred the patient to our medical center. After she was transferred, we found out about her pregnancy while taking the history. We used EUS to aspirate cyst and to avoid additional radiation exposure. Thereby we could classify it as mucinous cystic neoplasm. We explained to her about the standard radiation dose of CT in accordance with guidelines from The American Congress of Obstetricians and Gynecologists (ACOG). We also explained that fetal risks of anomalies and growth restriction are not usually increased with radiation exposure of less than $5 \operatorname{rad}^{2}$ and that the estimated maximum fetal dose for CT of abdomen was estimated about 2 to 3 rad. $^{3}$ After the explana-
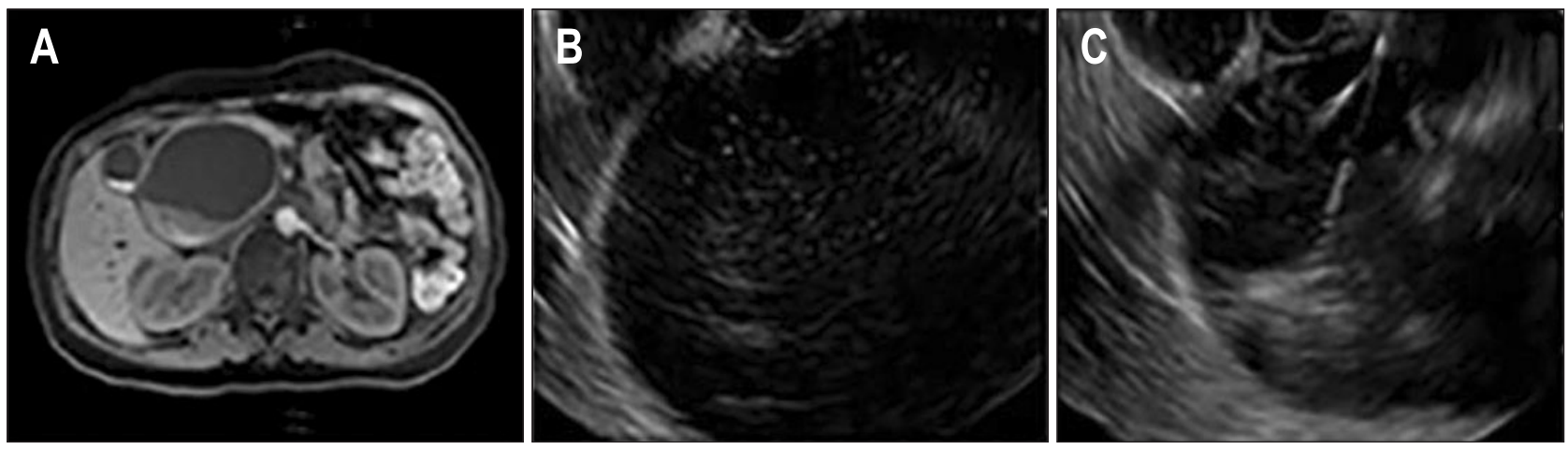

Fig. 2. After a large cystic dilatation was found on magnetic resonance imaging (A), an endoscopic ultrasonography (EUS) image was obtained (B), and simultaneous EUS-guided fine-needle aspiration was performed (case 12) (C). 
Table 1. Patients Undergoing Pancreatobiliary Interventions

\begin{tabular}{|c|c|c|c|c|c|c|}
\hline Case & Age, yr & Gestation, wk & Indication & Intervention & Fluoroscopy & Complication \\
\hline 1 & 32 & 28 & Obstructive jaundice & ERCP/EST & Yes & None \\
\hline 2 & 29 & 16 & Cholangitis & $\mathrm{ERCP} / \mathrm{EST}$ & Yes & None \\
\hline 3 & 32 & 19 & Gallstone pancreatitis & $\mathrm{ERCP} / \mathrm{EST}$ & Yes & None \\
\hline 4 & 35 & 20 & Obstructive jaundice & ERCP/EST & Yes & None \\
\hline 5 & 27 & 32 & Gallstone pancreatitis & $\mathrm{ERCP} / \mathrm{EST}$ & Yes & None \\
\hline 6 & 30 & 6 & Obstructive jaundice & ERCP/infundibulotomy & Limited* & Hyperamylasemia \\
\hline 7 & 22 & 18 & Gallstone pancreatitis & $\mathrm{ERCP} / \mathrm{EST}$ & Yes & None \\
\hline 8 & 27 & 9 & Traumatic pancreatitis & ERCP/stent insertion & Yes & None \\
\hline 9 & 41 & 7 & $\mathrm{MCN}$ & EUS-guided FNA & None & None \\
\hline 10 & 33 & 6 & Cholangitis & EUS & None & None \\
\hline 11 & 27 & 17 & Acute cholecystitis & EUS-guided GB aspiration & None & Acute pulmonary edema \\
\hline 12 & 33 & 20 & Choledochal cyst & EUS/ERCP/choledochoduodenostomy & None & None \\
\hline 13 & 32 & 21 & $\begin{array}{l}\text { Choledochal cyst } \\
\text { Cholangitis }\end{array}$ & EUS/ERCP/stent insertion & None & None \\
\hline
\end{tabular}

ERCP, endoscopic retrograde cholangiopancreatography; EST, endoscopic sphincterotomy; MCN, mucinous cystic neoplasm; EUS, endoscopic ultrasonography; FNA, fine-needle aspiration; GB, gallbladder.

*Limited: to minimize fluoroscopy time, radiographs were not taken, and bile aspiration was used to confirm selective bile duct cannulation.

tion, she decided to maintain her pregnancy and fortunately no developmental disorder was found in her baby.

Additional procedure was not necessary for some patients. For example, two patients presented with obstructive jaundice due to gallbladder (GB) and CBD stones (cases 1, 6). After ERCP was performed to remove CBD stone, GB stones were disappeared spontaneously after delivery in these patients. One patient also presented with obstructive cholangitis due to GB and CBD stones (case 10). However, after EUS was performed, CBD stone was disappeared already which seemed to be passed spontaneously.

On the other hand, some patients had to take additional therapy after therapeutic endoscopic procedures were performed. Five patients who had GB stones underwent laparoscopic cholecystectomy after delivery or during pregnancy (cases 2, 3, 4, 5, 7). Among those five, two patients underwent laparoscopic cholecystectomy during pregnancy (cases 2, 7). One was done electively on the fifth day after ERCP and the other was done with Cesarean delivery on the 30th day after ERCP. The rest one patient presented with acute cholecystitis on the 10th day after discharge and had to undergo percutaneous drainage of GB in the third trimester (case 11). The patient held to a drainage system until the day of delivery and delivered by Cesarean surgery. Soon after, the patient had a laparoscopic cholecystectomy additionally. The rest patients who had GB stones also underwent laparoscopic cholecystectomy after more than 6 months from delivery. And two patients who had choledochal cyst underwent bile duct resection surgery after delivery, additionally (cases 12, 13).

Complications occurred in two patients who had infundibu-

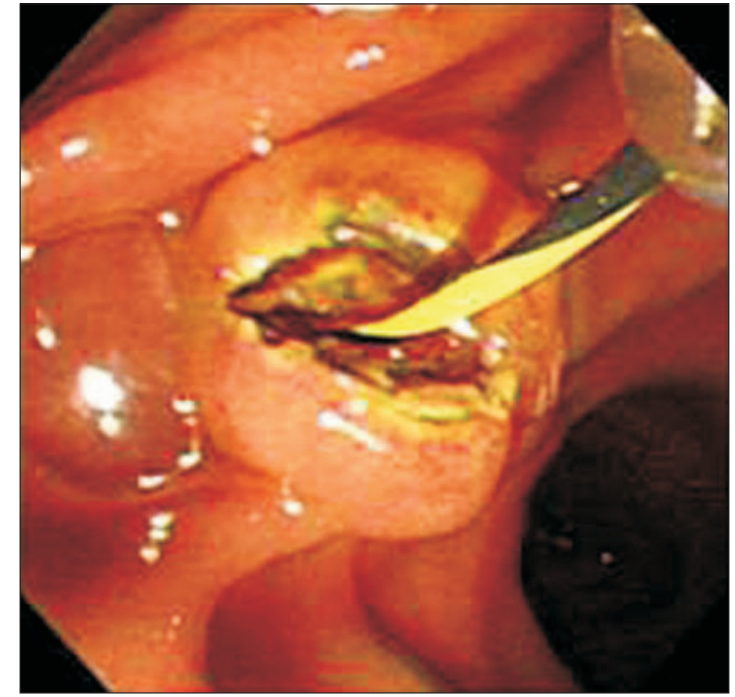

Fig. 3. A patient who underwent infundibulotomy developed hyperamylasemia (case 6).

lotomy and EUS-guided procedure respectively (Table 1). The patient who had infundibulotomy developed hyperaylasemia which responded well to conservative treatment (case 6). We did not take radiographs to lessen the fluoroscopy time and used a technique of bile aspiration to confirm selective bile duct cannulation (Fig. 3). And the other patient developed pulmonary edema (case 11). It was assumed that the pulmonary edema was related with ritodrine side effect and not with any procedures. When she arrived at our medical center, gynecologists administered a ritodrine to prevent preterm delivery as her cervical 
dilatation was proceeding. And we immediately performed EUSguided procedure for decompression of GB. She complained of dyspnea after the procedure, so chest X-ray was done and we found out that pulmonary edema had occurred (Fig. 4). Based on our discussion with gynecologists, we concluded that termination of pregnancy was needed to resolve pulmonary edema. Under the agreement of both the patient and her spouse, artificial abortion procedure was performed and she recovered from pulmonary edema.

A total of two artificial abortion procedures were performed in our patients. One patient was unmarried at that time and was unaware of her pregnancy (case 8). After ERCP, she informed us of her menstrual irregularity so we then considered the possibil-

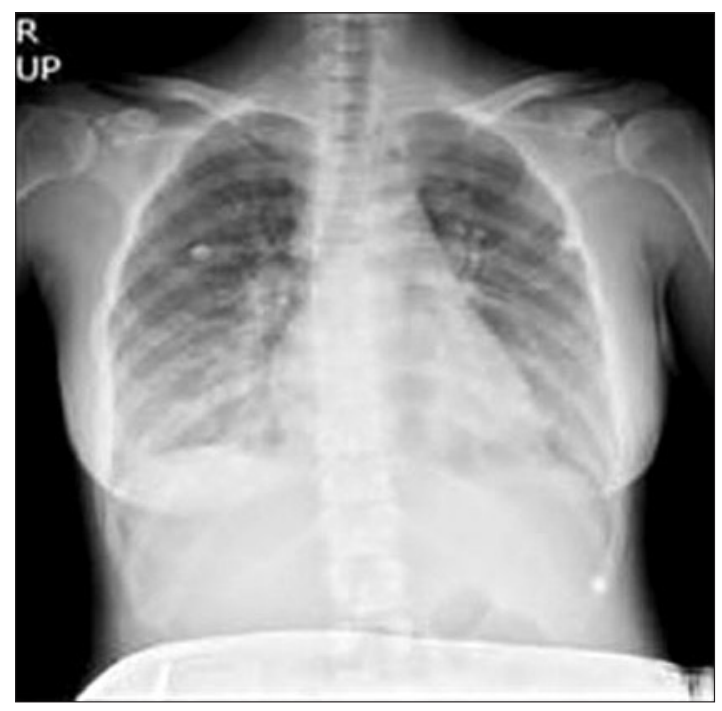

Fig. 4. After an endoscopic ultrasonography-guided procedure, pulmonary edema occurred (case 11). ity of pregnancy. Pregnancy test was done immediately and the test result was positive. Because she did not expect to have a baby, she decided to take an artificial abortion. Her gestational age was 9 weeks at that time. Based on data from atomic bomb survivors, it appears that the risk of central nervous system effects is greatest with exposure at 8 to 15 weeks of gestation. ${ }^{4,5}$ After discussion with gynecologists, we accepted her decision and she took an artificial abortion procedure. As we already mentioned above, the other artificial abortion procedure was performed due to medical condition (case 11).

Labor did not occur within 1 month of any procedure. Apart from above two cases, eleven pregnancies resulted in delivery of healthy babies with median APGAR scores of 9 and 10 at 5 and 10 minutes respectively. A total of eight infants were delivered to date and three were preterm infants. Five patients had a normal delivery and six patients had a Cesarean section delivery (Table 2). According to chart review of records from postpartum follow-up, all infants appeared to be healthy. We identified follow up results of all the 11 patients by phone in February 2014. And we confirmed that all children and babies had no developmental disability and mental retardation at that time.

\section{DISCUSSION}

Symptomatic gallstone disease in pregnancy is common and it has been related with increased mortality risk for the mother and fetus. ${ }^{6}$ In the gestational stages, complications may occur such as spontaneous abortion, fetal abnormalities, premature labor and even death. In a study by Tang and associates, ${ }^{1}$ they reported data from 65 pregnant women who underwent ERCP. Result from this report shows that the lower rate of term pregnancy (73.3\%), the higher rate of preterm delivery (20.0\%), and low birth weight (21.4\%) are more common when interventions

Table 2. Pregnancy and Fetal Outcomes

\begin{tabular}{|c|c|c|c|c|c|c|}
\hline Case & Age, yr & Gestation, wk & Preterm delivery (wk) & Cesarean section & Fetal outcome (kg) & Abortion \\
\hline 1 & 32 & 28 & None & None & Healthy & None \\
\hline 2 & 29 & 16 & None & None & Healthy & None \\
\hline 3 & 32 & 19 & Yes (36) & None & Healthy & None \\
\hline 4 & 35 & 20 & Yes (36) & Yes & LBW (1.86) & None \\
\hline 5 & 27 & 32 & None & Yes & Healthy & None \\
\hline 6 & 30 & 6 & None & Yes & Healthy & None \\
\hline 7 & 22 & 18 & None & None & Healthy & None \\
\hline 8 & 27 & 9 & - & - & Fetal loss & Yes (artificial) \\
\hline 9 & 41 & 7 & None & Yes & Healthy & None \\
\hline 10 & 33 & 6 & None & None & Healthy & None \\
\hline 11 & 27 & 17 & - & - & Fetal loss & Yes (artificial) \\
\hline 12 & 33 & 20 & None & Yes & Healthy & None \\
\hline 13 & 32 & 21 & None & Yes & Healthy & None \\
\hline
\end{tabular}

LBW, low birth weight. 
are required during the first trimester.

In this report, there are four patients who underwent pancreatobiliary endoscopic procedures during the first trimester. Two patients underwent ERCP and the other two underwent EUS during the first trimester. After ERCP was performed, one patient decided to take an artificial abortion because she was unaware of her pregnancy before the procedure. Others had a term pregnancy and delivered healthy babies. On the other hand, three patients who underwent ERCP during the second trimester had a preterm delivery (cases 3, 4, 13). Patient \#4 was 35 years old and had an experience of preterm delivery twice before. Thus, we assumed that her preterm delivery is not related with the procedures, but with her age and previous history of preterm delivery. And it was assumed that advanced maternal age could have affected the preterm delivery of the other two patients.

The radiation exposure from fluoroscopy during pregnancy has been a main concern because of its potential harmful effects on fetus. In humans, growth restriction, microcephaly, and mental retardation are the most common adverse effects from high-dose radiation. ${ }^{3,47}$ Fetal malformations, growth retardation, and intrauterine death have a threshold dose of 100 to $200 \mathrm{mGy}^{8}{ }^{8}$ These doses are not typical for general diagnostic radiology, particularly when the fetus lies outside of the primary beam, as with ERCP. ${ }^{9,10}$ According to the guidelines from ACOG, exposure of less than 5 rad or 50 mGy does not seem to be related with a noticeable increased rate of fetal anomalies or pregnancy loss. $^{2}$ And International Commission on Radiological Protection (ICRP) proposed threshold of 100 mGy about probability of bearing healthy children. ${ }^{11}$ In prior studies, estimated dose of fetal radiation exposure have been ranged from 0.1 to 3 mGy per procedure (Table 3). ${ }^{12,13}$

In the study of Samara and associates, ${ }^{9}$ their data revealed that fetal dose exposure can be variable ranging from 3.4 to 55.9 mGy. It shows that fetal radiation exposure dose during ERCP can exceed 50 mGy as stipulated in ACOG guideline. According to ICRP recommendation, this range of radiation exposure dose seems to be safe for fetus. But it is, in fact, difficult to estimate precise conceptus dose as described in the study by Samara. Thus, more efforts are required to reduce radiation ex- posure to fetus.

Baron and Schueler ${ }^{10}$ described methods for radiation dose reduction. The methods include limiting fluoroscopy time, using low dose settings and the smallest possible field that is available, and using lead-shielding between the patient and beam.

Smith and colleagues ${ }^{14}$ recently presented data to reduce radiation exposure by minimizing fluoroscopy time. ERCP was performed by biliary endoscopists performing more than 500 cases a year in their study. The study shows that estimated conceptus doses were below $0.5 \mathrm{mGy}$ in most cases.

In other reports, nonfluoroscopic techniques to cannulate the papilla of Vater were effective and safe for both mother and fetus. ${ }^{12,15,16}$ And Yang and associates ${ }^{17}$ described their experiences with ERCP without fluoroscopy in 24 pregnant patients who had a severe acute biliary pancreatitis. All patients underwent emergent ERCP and endoscopic nasobiliary drainage (ENBD) without fluoroscopy. After stabilization, patients in early or mid pregnancy underwent endoscopic retrograde biliary drainage (ERBD) with second ERCP without fluoroscopy. And their stents and CBD stones were removed by third ERCP after delivery. In late pregnancy, patients underwent second ERCP with fluoroscopy to remove CBD stone after delivery. There was no serious complication except mild hemorrhage in two patients. They showed a method to avoid radiation exposure during pregnancy by using ERBD and ENBD.

Oftentimes, it is difficult to estimate radiation exposure dose accurately. Thus, ERCP should be performed with careful use of fluoroscopy or nonfluoroscopic techniques to reduce radiation exposure as stated above.

EUS can be also used as an alternative and ancillary procedure to ERCP. In a study by Lee and associates, ${ }^{18}$ they investigated the benefits and safety of a EUS-guided versus ERCPguided approach in the management of biliary obstructive disease. In the EUS group, therapeutic ERCP was performed if a lesion was found during EUS. And therapeutic treatment was performed at the discretion of the endoscopist in the ERCP group. More patients had serious complications such as bleeding, acute pancreatitis, and umbilical abscess in the ERCP group. And they came to the conclusion that EUS is a safe and

Table 3. Estimated Radiation Dose to Fetus during Pregnancy

\begin{tabular}{ccccc}
\hline First author & Year of publication & No. of patients & Fluoroscopy time, mean (range) & Estimated conceptus dose, mGy \\
\hline Tham $^{12}$ & 2003 & 15 & $3.2 \min (1.1-6.1)$ & $3.1(1.02-5.77)$ \\
Kahaleh $^{13}$ & 2004 & 17 & $14 \sec (1-48)$ & $0.4(0.01-1.8)$ \\
Samara $^{9}$ & 2009 & 24 (nonpregnant*) $^{*}$ & Not available & $3.4-55.9$ \\
Smith $^{14}$ & 2013 & 35 & 0.15 min $(0-1)$ & $n=23 ;$ negliable $(<0.1)$ \\
& & & $n=8 ; 0.1-0.2$ \\
& & & $n=3 ; 0.2-0.5$ \\
\end{tabular}

*Nonpregnant: Samara and colleagues presented data that were obtained from 24 nonpregnant patients to estimate the fetal dose exposure. 
accurate test to select patients for therapeutic ERCP in patients suspected to have biliary obstructive disease. We used EUS to examine CBD stone or to diagnose choledochal cyst (cases 9, 10). In addition, EUS was used as a guidance for other procedures in our study (cases 11, 12, 13). There were no procedurerelated complications and fetal morbidity.

In a case where endoscopist failed to approach by ERCP, percutaneous transhepatic biliary drainage (PTBD) can also be an alternative procedure. However, when any special conditions like pregnancy, considering radiation exposure and invasiveness of PTBD, it seems to be more favorable to use EUS rather than PTBD or repetitive attempt of ERCP.

It is well known that gallstone pancreatitis can recur if cholecystectomy is not performed. In our cases, laparoscopic cholecstectomy were done in five pregnant women (cases 2, 3, $4,5,7)$. Two (cases 2, 7) had an operation during the second trimester (18 weeks and 22 weeks, respectively) and the rest three patients (cases 3, 4, 5) had a surgery during or after delivery. Among them, two (cases 3,4) had a surgery after delivery who were diagnosed at their second trimester. They had a preterm delivery and one infant (case 4) had a low birth weight. We could not conclude whether surgical delay had affected on their pregnancy outcome directly considering their advanced maternal age and a history of preterm delivery. Generally, delivery at an older age and previous history of preterm delivery are well known risk factors for preterm delivery. Thus, we analyzed the result not only based on surgical delay or any procedure-related factors but on their advanced maternal age and previous history of preterm delivery.

According to the Society of American Gastrointestinal and Endoscopic Surgeons guideline, laparoscopic treatment of acute abdominal disease has the same indications in pregnant and nonpregnant patients. ${ }^{19}$ And the consensus among surgeons is that second trimester is the safest period to perform surgery during pregnancy. ${ }^{20,21}$ However, there were studies which reported early contraction and premature birth or spontaneous abortion with the laparoscopic cholecystectomy although it was done at the second trimester. ${ }^{22-24}$ Most reports concerning ERCP during pregnancy have concluded that there is no procedure related pregnancy or fetal morbidity with safety measures. Because surgery is more invasive than endoscopic procedures, if the effect of surgery and endoscopic procedures on pregnancy is comparable, it is favorable to choose endoscopic procedures which are less invasive.

Thus, if pregnant patients who have biliary disease are stable after endoscopic procedures, it seems to be more favorable to consider delaying cholecystectomy until delivery rather than performing it during pregnancy. But if patients still have a symptom after endoscopic procedures or acute indication for surgery, it will be desirable to consider immediate laparoscopic cholecystectomy.

Sphincterotomy can be an alternative method for cholecys- tectomy in patients who need to prevent recurrent cholangitis or pancreatitis during pregnancy. Barthel and associates ${ }^{25}$ have presented that ERCP with sphincterotomy prevented recurrence of gallstone pancreatitis. Also in our cases, two patients who only underwent a sphincterotomy and not cholecystectomy had no recurrence of gallstone pancreatitis during pregnancy (cases 1, 6).

For sedation, we administered medications such as midazolam, meperidine, fentanyl, or propofol during procedures. We gave a meperidine to all patients and six of them took a midazolam additionally. None of the patients had complications such as arrhythmia and respiratory depression. One patient had a low birth weight $(1.86 \mathrm{~kg})$ infant with preterm delivery. However, it does not seem to be related with administered medications or procedures but with her history of preterm delivery and advanced maternal age (case 4). The U.S. Food and Drug Administration classifies benzodiazepines as a category D. Neonatal withdrawal syndromes and respiratory depression are associated with regular use of benzodiazepine. However, medications for conscious sedation that belong to benzodiazepine has been used during ERCP in many reported cases. And congenital abnormalities are unlikely to occur in association with ERCP. ${ }^{26}$ But if possible, midazolam should be avoided in the first trimester.

Although the number of cases was limited, our data help demonstrate the efficacy and safety of ERCP and therapeutic interventions such as stent placement, sphincterotomy, and EUSguided procedures during pregnancy. In addition, we showed that EUS can be used in pregnant women as an alternative and ancillary procedure to ERCP. There were two women who did not inform the medical staff of their pregnancy before ERCP and other radiation imaging test. According to our cases, we suggest that careful history taking and pregnancy test are needed for all female patients who are in their reproductive age. Further studies with large sample size are required to assess our findings in this study.

In conclusion, pancreatobiliary procedures seem to be effective and safe when performed with careful use of fluoroscopy and appropriate safety measures.

\section{CONFLICTS OF INTEREST}

No potential conflict of interest relevant to this article was reported.

\section{REFERENCES}

1. Tang SJ, Mayo MJ, Rodriguez-Frias E, et al. Safety and utility of ERCP during pregnancy. Gastrointest Endosc 2009;69(3 Pt 1):453461.

2. Brent RL. The effect of embryonic and fetal exposure to x-ray, microwaves, and ultrasound: counseling the pregnant and nonpregnant patient about these risks. Semin Oncol 1989;16:347-368. 
3. Cunningham FG, Gant NF, Leveno KJ, Gilstrap LC 3rd, Hauth JC, Wenstrom KD. General considerations and maternal evaluation. In: Cunningham FG, Williams JW, eds. Williams obstetrics. 21st ed. New York: McGraw-Hill, 2001:1143-1158.

4. Hall EJ. Scientific view of low-level radiation risks. Radiographics 1991;11:509-518.

5. National Research Council; Committee on the Biological Effects of Ionizing Radiations. Other somatic and fetal effects. In: National Research Council; Committee on the Biological Effects of Ionizing Radiations. Health effects of exposure to low levels of ionizing radiation: Beir V. Washington, DC: National Academy Press, 1990:352370.

6. Valdivieso V, Covarrubias C, Siegel F, Cruz F. Pregnancy and cholelithiasis: pathogenesis and natural course of gallstones diagnosed in early puerperium. Hepatology 1993;17:1-4.

7. Otake M, Yoshimaru H, Schull WJ. Severe mental retardation among prenatally exposed survivors of the atomic bombing of Hiroshima and Nagasaki: a comparison of the T65DR and DS86 dosimetry systems. Hiroshima: Radiation Effects Research Foundation, 1988

8. International Commission on Radiological Protection. Pregnancy and medical radiation. Ann ICRP 2000;30:iii-viii, 1-43.

9. Samara ET, Stratakis J, Enele Melono JM, Mouzas IA, Perisinakis $\mathrm{K}$, Damilakis J. Therapeutic ERCP and pregnancy: is the radiation risk for the conceptus trivial? Gastrointest Endosc 2009;69:824831.

10. Baron TH, Schueler BA. Pregnancy and radiation exposure during therapeutic ERCP: time to put the baby to bed? Gastrointest Endosc 2009;69:832-834.

11. International Commission on Radiological Protection. Pregnancy and medical radiation. Oxford: Pergamon, 2000.

12. Tham TC, Vandervoort J, Wong RC, et al. Safety of ERCP during pregnancy. Am J Gastroenterol 2003;98:308-311.

13. Kahaleh M, Hartwell GD, Arseneau KO, et al. Safety and efficacy of ERCP in pregnancy. Gastrointest Endosc 2004;60:287-292.

14. Smith I, Gaidhane M, Goode A, Kahaleh M. Safety of endoscopic retrograde cholangiopancreatography in pregnancy: fluoroscopy time and fetal exposure, does it matter? World J Gastrointest En- dosc 2013;5:148-153.

15. Rahmin MG, Hitscherich R, Jacobson IM. ERCP for symptomatic choledocholithiasis in pregnancy. Am J Gastroenterol 1994;89: 1601-1602.

16. Zagoni T, Tulassay Z. Endoscopic sphincterotomy without fluoroscopic control in pregnancy. Am J Gastroenterol 1995;90:1028.

17. Yang J, Zhang X, Zhang X. Therapeutic efficacy of endoscopic retrograde cholangiopancreatography among pregnant women with severe acute biliary pancreatitis. J Laparoendosc Adv Surg Tech A 2013;23:437-440.

18. Lee YT, Chan FK, Leung WK, et al. Comparison of EUS and ERCP in the investigation with suspected biliary obstruction caused by choledocholithiasis: a randomized study. Gastrointest Endosc 2008;67:660-668.

19. Reedy MB, Galan HL, Richards WE, Preece CK, Wetter PA, Kuehl TJ. Laparoscopy during pregnancy: a survey of laparoendoscopic surgeons. J Reprod Med 1997;42:33-38.

20. Patel SG, Veverka TJ. Laparoscopic cholecystectomy in pregnancy. Curr Surg 2002;59:74-78.

21. Abuabara SF, Gross GW, Sirinek KR. Laparoscopic cholecystectomy during pregnancy is safe for both mother and fetus. J Gastrointest Surg 1997;1:48-52.

22. Glasgow RE, Visser BC, Harris HW, Patti MG, Kilpatrick SJ, Mulvihill SJ. Changing management of gallstone disease during pregnancy. Surg Endosc 1998;12:241-246.

23. Graham G, Baxi L, Tharakan T. Laparoscopic cholecystectomy during pregnancy: a case series and review of the literature. Obstet Gynecol Surv 1998;53:566-574.

24. Barone JE, Bears S, Chen S, Tsai J, Russell JC. Outcome study of cholecystectomy during pregnancy. Am J Surg 1999;177:232236.

25. Barthel JS, Chowdhury T, Miedema BW. Endoscopic sphincterotomy for the treatment of gallstone pancreatitis during pregnancy. Surg Endosc 1998;12:394-399.

26. Cappell MS. The fetal safety and clinical efficacy of gastrointestinal endoscopy during pregnancy. Gastroenterol Clin North Am 2003;32:123-179. 